\title{
Os butiazeiros e a Rota dos Butiazais, sementes de cuidado e conexão
}

\author{
Márcia Kaster Portelinha ${ }^{\mathrm{a}^{*}}$, Rosa Lia Barbieri ${ }^{\mathrm{b}}$, Péricles da Silva Godinho ${ }^{\mathrm{a}}$, \\ Camila Almeida ${ }^{a}$
}

${ }^{a}$ Universidade Federal de Pelotas - UFPel, Pelotas, RS, Brasil

bembrapa Clima Temperado, Pelotas, RS, Brasil

\section{Histórico do Artigo \\ Recebido em: \\ 15/04/2020 \\ Aceito em: \\ $22 / 05 / 2020$}

\section{Palavras-chave:}

Ecossistema;

infância;

biodiversidade

\begin{abstract}
RESUMO
A Rota dos Butiazais é uma rede que conecta pessoas para a conservação e uso sustentável da biodiversidade associada aos ecossistemas dos butiazais. Este trabalho teve o objetivo de descrever a importância do butiazeiro para os integrantes da Rota dos Butiazais. Pesquisa qualitativa, descritiva, realizada durante o II Encontro Internacional da Rota dos Butiazais, na Embrapa Clima Temperado, em Pelotas (RS). Foram realizadas entrevistas semiestruturadas, gravadas e transcritas. Foi utilizada análise de conteúdo temática. Os participantes foram 14, sendo quatro argentinos, dois uruguaios e oito brasileiros. A partir da análise das entrevistas afloraram 07 núcleos de sentido: proximidade e intimidade com os butiazeiros; importância do butiá; preocupação com o risco de extinção; biodiversidade e preservação do ecossistema que se relaciona com o butiazeiro; utilização do butiazeiro como planta ornamental; a identidade que se cria em locais que têm butiazeiros; propriedades medicinais do butiazeiro. Foi exposto a respeito da importância atual e futura da planta, sua capacidade de agregar outras espécies, e de como essas pessoas aprenderam a trabalhar o butiazeiro em conjunto com o restante do espaço e do trabalho.
\end{abstract}

The Butia palm and the Butia Palm Groves Network, care and connection seeds
Keywords:

Ecosystem;

Childhood;

Biodiversity

\section{ABSTRACT}

The Butia Palm Groves Network is a network that connects people with common interests for conservation and sustainable use of biodiversity associated to the Butia palm groves ecosystems. The objective of this qualitative and descriptive research was to describe the Butia importance for the members of the Butia Palm Groves Network. The study was done during the II International Meeting of the Butia Palm Groves Network at Embrapa Clima Temperado, in Pelotas (RS, Brazil). Semi-structured interviews were carried out, which were recorded and transcribed. The data were analyzed according to thematic content analysis. 14 people took part of this study, being four Argentines, two Uruguayans and eight Brazilians. The data analysis has resulted into seven categories: closeness and intimacy with the Butia palm groves; importance of the Butia; concern about the risk of extinction; biodiversity and preservation of the ecosystem related to the Butia palm; use of palm as ornamental plant; the identity that is created in places were there are Butia palms; medicinal properties of Butia palm. The current and future importance of the plant is related to its ability to aggregate other species, besides offering to people the possibility to work with the Butia palm groves together with the environment (nature) and the social bonds (working environment).

\section{Introdução}

O entendimento de que fazemos parte do todo e o todo faz parte de nós, nos coloca a repensar posições e ações. Nesse pensamento a manutenção da qualidade ambiental precisa estar conectada ao uso dos recursos naturais, assim como o uso precisa estar associado à sua conservação. Nesse sentido, aliadas ao conhecimento científico, as identidades afetivas e culturais são elementos necessários para o sucesso na conservação da biodiversidade $(1,2)$.

Os ecossistemas de butiazais, estão ameaçados e mostram avançado estado de

\footnotetext{
*Autor correspondente: portelinhamarcia@gmail.com (Portelinha M.K.)
} 
degradação no Rio Grande do Sul, o que torna imprescindíveis ações de manejo sustentável das populações remanescentes, com ênfase na conservação da variabilidade genética (3). Os butiazeiros vêm sofrendo constantemente as consequências da ação antrópica, especialmente devido a três fatores principais: a implantação de monoculturas, a pecuária extensiva e a urbanização, especialmente nas áreas litorâneas. Tal processo põe em risco a sobrevivência dos butiazais em longo prazo (4).

As espécies do gênero Butiá são palmeiras (família Arecaceae), conhecidas popularmente como butiazeiros, os quais produzem frutos comestíveis conhecidos como butiás (5). Esse gênero reúne 20 espécies na América do Sul, distribuídas no Brasil, Uruguai, Argentina e Paraguai (6). Dentre essas espécies, Butia odorata é a que apresenta distribuição mais ao sul, sendo nativa no Bioma Pampa, ocorrendo somente no Rio Grande do Sul (no Brasil) e nos departamentos do leste do Uruguai (7).

Partindo do pressuposto de que se conserva o que se conhece, e com pensamento na preservação, ações vem sendo conduzidos para gerar informações e valorizar a biodiversidade relacionada aos ecossistemas de butiazais. A caracterização de serviços ambientais, identificação da flora e da fauna associada, estudos da biologia reprodutiva e resgate do conhecimento popular associado aos usos do butiá têm contribuído para a redução das ameaças aos butiazais, com a valorização desses ecossistemas como prestadores de serviços ambientais (8).

Para realizar as ações citadas acima, foram executados vários projetos de pesquisa e desenvolvimento com o objetivo de produzir avanços no conhecimento científico, divulgar e capacitar as pessoas no uso dos butiás. Ideias como essas almejam sensibilizar as comunidades, e com isso incentivar a valorização da biodiversidade existente nos ecossistemas de butiazais (9).

Nesse movimento e com vários atores envolvidos, em 2015 foi proposta a "Rota dos Butiazais", uma rede conectando pessoas para a conservação e uso sustentável da biodiversidade associada a esses ecossistemas. A Rota dos Butiazais contempla várias espécies de butiá, além da flora e fauna nativas associadas aos ecossistemas de butiazais no Sul do Brasil, Uruguai e Argentina (11).

A primeira articulação para a criação da Rota dos Butiazais foi realizada em maio de 2015, em Brasília, em uma reunião entre representantes da Embrapa Clima Temperado e do Ministério do Meio Ambiente (12). Essa rede realiza exposições de fotos, vídeos, programas de televisão, entrevistas no rádio, ofertas de oficinas de culinária e artesanato com butiá, oficinas de educação ambiental, seminários e palestras. Com essas atividades tem sido possível divulgar e sensibilizar a sociedade em geral para a importância dos butiazais (11).

Na teoria de Serge Moscovici, conjuntamente com ações, acontecem as representações sociais, que se desenvolvem justamente no compartilhamento da história social, de percepções, sentimentos, concepções a respeito do universo coletivo. Essas só se tornam possíveis através da comunicação e interação dos sujeitos em grandes e pequenas comunidades e com o espaço que os rodeia (13).

Essa teoria pode ser definida como o conjunto de construções de sentido através das relações e interações cotidianas dos sujeitos pertencentes a determinado grupo. Ou seja, as representações são formas de conhecimento socialmente elaborado, compartilhado e de ordem prática. Tudo isso na acepção de que representar significa intervir (14).

Finalizando a introdução, expõe-se que este projeto buscou trazer ideias, que se estabelecem no compartilhamento de histórias e vivências dos integrantes da Rota dos Butiazais em relação aos butiazeiros. Neste contexto, justifica-se essa composição de dados, balizada pela Teoria das Representações Sociais, que almejou resgatar esses pensamentos e teve como objetivo descrever a importância do butiazeiro para integrantes 
da Rota dos Butiazais.

\section{Materiais e Métodos}

Foi realizada uma pesquisa de método qualitativo, com abordagem descritiva. O trabalho foi desenvolvido durante o II Encontro Internacional da Rota dos Butiazais, na Embrapa Clima Temperado, em Pelotas (RS, Brasil), de 21 a 22 de agosto de 2018.

A amostra foi composta por 14 pessoas, sendo quatro argentinos, dois uruguaios e oito brasileiros integrantes da Rota dos Butiazais. Essas pessoas foram indicadas pela coordenadora da Rota dos Butiazais, que utilizou como critérios de inclusão: ser integrante ativo da rede; estar participando do evento citado acima e aceitar participar do trabalho. Como critérios de exclusão: não aceitar gravar a entrevista.

A coleta de dados foi realizada através de entrevistas semiestruturadas, gravadas e transcritas. As mesmas foram compostas por 10 perguntas, realizadas em sala separada, no mesmo prédio do evento. Neste trabalho, foi analisado todo material transcrito das entrevistas, que respondesse ao objetivo citado na introdução.

As questões realizadas e utilizadas no manuscrito foram: Há quanto tempo existe o butiazal que conhece? A quanto tempo conhece esse ambiente do butiazal? Faz uso frequente do butiazal? Pensa que o butiazal influencia na atividade direta? Tem atividade frequente com butiazeiros, diária? Considera importante o butiazal para a comunidade do entorno? Qual seria a importância do butiazeiro para a natureza? Quais são as principais atividades na área do butiazal? Os butiazais quando eles existem, favorecem que atividades? $\mathrm{O}$ que considera importante para que as atividades nos butiazais se mantenham?

A organização dos dados foi realizada a partir da análise de conteúdo, esse processo teve início com uma leitura flutuante, posteriormente foram sendo realizadas leituras aprofundadas, nas quais foram aflorando temas, que conforme Laurence Bardin (15), são unidades de significação que se libertam naturalmente de um texto analisado segundo certos critérios relativos à teoria que serviu de guia para à leitura. Seguindo essa ideia a teoria balizadora foi a de Serge Moscovici (13), Teoria das Representações Sociais trazida na introdução e na discussão deste trabalho.

Dos temas, foram sendo organizadas as categorias, passagem dos dados brutos, para dados organizados, essa ação se deu em duas etapas: no inventário foram isolados os elementos e na classificação a qual se deu por acervo, o título conceitual de cada categoria somente foi sendo definido no final da operação (15).

A partir da análise e organização do material, foram desenvolvidas 07 categorias, designadas: $\mathrm{C} 1$ (proximidade e intimidade com o butiazeiro na infância); C2 (importância do butiá); C3 (preocupação com o risco de extinção); C4 (biodiversidade e preservação do ecossistema que se relaciona com o butiazeiro); C5 (utilização do butiazeiro como planta ornamental); C6 (a identidade que se cria em locais que têm butiazeiros) e; C7 (propriedades medicinais do butiazeiro).

Foram respeitados os aspectos éticos, tendo parecer favorável $\mathrm{n}^{\circ} 2.565 .059$ pelo Comitê de Ética em Pesquisa da Universidade Federal de Pelotas - Faculdade de Enfermagem e Obstetrícia.

\section{Resultados}

Os informantes deste trabalho foram 14 integrantes da Rota dos Butiazais, sendo eles 04 argentinos, dois uruguaios e 08 brasileiros. Em relação à profissão, foram entrevistadas/os artesãs, confeiteiras, extrativistas, fazendeiros/as, agricultores/as, 
empresários/as e ambientalistas.

As categorias encontradas foram sete, as quais foram disponibilizados de forma a expor os conteúdos das entrevistas, com intuito de organizar e demonstrar as falas dos informantes.

C1: "proximidade e intimidade com o butiazeiro na infância".

"Desde criança, usava ele no bodoque, quebrava para comer a amêndoa, para jogar bolita também, porque tem uns que são bem redondinhos. (MG).

"Olha, desde que eu conheço a minha cidade [...], eu vim com 8 anos, e aí já conheci os butiás, ...dentro da área do município e também da região [...] desde a infância, tem pés de butiá" (RJ).

"... desde que eu nasci, eu conheço o butiazal, ...essa propriedade está na nossa família há 91 anos, ...ele não foi plantado por nós” (CHB).

"... eu conheço butiazeiros desde criança porque, na verdade, nós socávamos coquinho em casa, eu e o meu irmão, em casa tinha só um pé de butiá” (GSM).

"Eu nasci nos palmares, com minha família, um passeio tradicional, de turismo, era pegar esses frutos, um passeio, muito comum" (MCV).

"... toda minha vida, porque este butiazal que eu trabalho é uma propriedade de família, quando era pequena passava o tempo lá” (MEP).

Nas entrevistas, os participantes narraram a presença do butiá desde a infância, as falas evidenciaram o convívio com a planta, a utilização nas brincadeiras, indicando uma relação de proximidade e boas lembranças.

C2: "importância do butiá".

"Se não está influenciando agora, futuramente irá influenciar, ele é uma das frutas que eu considero carro chefe" (MG).

"O butiazeiro tem aquela capacidade nucleadora, que favorece encontros de várias outras espécies” (GSM).

“... os butiazeiros são de extrema importância, para mim, para minha família, e para quem vive na volta” (JM).

“... nós aprendemos a trabalhar tanto com o plantio da lavoura, quanto com os butiazeiros, nós fizemos um conjunto, virou união, parceria entre o ser humano e a natureza" (JM).

“... para manter os ecossistemas e os ecossistemas florestais também” (MEP).

“... os palmares são um componente de um ecossistema deste lugar e, portanto, uma estratégia de conservação da biodiversidade” (AM).

“... as pessoas têm uma referência de Santa Vitória do Palmar, de ter uma grande quantidade de palmares. No momento, as pessoas estão focando mais, resgatando a história dos butiás, porque a história dos butiás, é da nossa cidade, é um resgate, cultural, e é a nossa planta" (MBI).

“... não estamos trabalhando com refrigerante, é um produto da sociobiodiversidade que não tem em outros locais no mundo...” (AAMS).

Nessa categoria a importância do butiá foi destacada no relato dos integrantes da Rota dos Butiazais, como marca de uma identidade singular e coletiva, da cultura, onde o butiá faz parte da história e esse sentimento, faz com que se pense na conservação dos ecossistemas de butiazais.

C3: "preocupação com o risco de extinção".

"Muito importante, porque hoje eles estão em risco de extinção, então quanto mais se mostra o nosso trabalho, melhor. Onde eu vou sempre levo mudinhas de butiá, então conscientiza mais as pessoas, para cuidarem..." (MBI).

“..., então eu penso que as autoridades têm que se envolver mais, colocar-se mais à 
disposição da comunidade, na questão da preservação e conservação do butiá" (AAMS).

"... eles são fundamentais, o butiazal está integrado ao ecossistema de preservação dessas áreas, principalmente em área condensada..." (GSM).

No seguimento dos relatos, observou-se uma preocupação com o risco de extinção da planta e a necessidade de cuidado com a preservação da área do butiazal, e a pouca disponibilidade de apoio das autoridades a respeito.

C4: "biodiversidade e preservação do ecossistema que se relaciona com o butiazeiro"

“... para fauna local, uma diversidade, uma fruta que não tem naquela época com as qualidades dela, então traz muito bichinho ali para a volta, insetos..." (MG).

“... a gente percebe, assim, que em época de floração, as abelhas, os insetos, pegam o butiá, os pássaros também, e a própria questão da biodiversidade, movendo a fauna..." (RJ).

"... quando se fala em butiazal, se imagina uma coleção de butiazeiros, mas tem toda uma coleção de aves, toda uma biodiversidade, se tem muitos animais silvestres, que está comprovado que se alimentam de butiá. Tem outros animais que não se alimentam de butiá, mas que se alimentam dos que se alimentam... Então, tem toda uma cadeia, de comida, de pássaros, répteis, sapos, enfim... mamíferos de pequeno e grande porte, são muitos animais" (CHB).

"... tem uma biodiversidade tão grande dentro desse butiazal. A quantidade de animais que vivem nos butiazais...” (FT).

“... porque além de fornecer o fruto, são áreas de proteção aos animais. Às vezes são áreas tão fechadas de butiás, que também são áreas de repouso para os animais, dormitório para os animais. Além dos animais se beneficiarem com os frutos, eles se beneficiam com a estrutura" (FT).

"... porque a gente ainda tem animais silvestres, que dependem e se alimentam do butiá. Dependem desse fruto, então eu creio que é a cadeia..." (GSM).

“... Também no inverno ele é um alimento para o gado comer, porque no inverno é difícil a pastagem, por isso onde o gado alcança, fica de alimento para eles" (JM). "... o benefício ambiental, a palmeira abriga animais, a fauna. Tem uma mata próxima, com animais silvestres... temos mais de 120 aves e outros animais...” (MEP).

“... pôr a palmeira ser protegida, protege os animais." (MEP).

"Os butiazais favorecem as atividades que tem ao entorno, por exemplo a criação de gado...não ocupa tanto espaço, não impede o desenvolvimento do campo, podem compartilhar" (MP).

“... a gente se junta com outras entidades, para justamente fazer um trabalho de conservação e mostrar para todos, a questão da fauna, da flora...” (AAMS).

“... existem pequenos roedores, pássaros se alimentando diretamente dessas palmeiras... manter isso, para que mantenha esses roedores, e todos os pássaros e, por conseguinte, seus predadores" (AAMS).

"... também vinculado a isso se criou um refúgio de vida silvestre...” (AM).

Nessas falas se observa o olhar amplo dessas pessoas em relação ao entorno, a estrutura que rodeia o ecossistema dos butiazais e em relação a biodiversidade. Essa ajuda mútua, soma e troca de benefícios, faz com que todos tenham interação e de certa forma se apoiem e contribuam para a preservação e manutenção das espécies que ali habitam. A fauna em específico se beneficia da sombra, do caule, frutos e também ajuda no reflorestamento dos butiazeiros, quando espalha seus coquinhos. A flora além de se abrigar, vive e convive com o butiazeiro e aumenta sua beleza natural.

C5: "utilização do butiazeiro como planta ornamental".

“... e a flora, e a ornamentação também da cidade, é muito em pátios, o paisagismo" $(R J)$. 
“... além disso, além da beleza cênica, paisagística, de contemplar muita vida...” $(\mathrm{CHB})$.

“... lá em casa, por exemplo, a gente tem orquídeas que nascem no butiazal, então tá tudo muito conectado. Eu acho que o grande segredo é como fazer para que isso se torne importante para a cidade..." (GSM).

Sobre a beleza natural da planta butiazeiro, e que também se aprimora com outras espécies fixadas nela e ao seu redor, se observa uma conecção que muitas vezes acontece e se forma, sem a mão humana. As falas trazem o sentido simbiose, entre algumas plantas e o butiazeiro. Os entrevistados acreditam que se mostrando esse conjunto as muitas pessoas que não os conhece, ou que, não os observou, pode ser uma forma de chamar a atenção, e com isso mostrar o porquê essa espécie pode e deve ser preservada.

C6: "a identidade que se cria em locais que têm butiazeiros".

“... o butiá também pode dar identidade desse lugar, porque quando tu moras em um lugar que tem um butiazal, entra em contato com este espaço...” (CHB).

"... tu ficas mais feliz de morar nesse lugar, hoje o povo de Tapes diz assim: "Eu sou de um lugar onde tem butiá". E nós, aqui, hoje, quantas pessoas estão envolvidas ao redor desse gênero, o Butia Odorata..." (CHB).

"... Eles tiveram um papel muito forte, se criou uma identidade das populações em torno dos palmares" (AM).

"... parece que é algo que enriquece o lugar, é algo tão natural, que parece que não poderia faltar nunca” (MPI).

Nessa categoria, foi dito que locais que contém essa planta criam uma identidade, demonstrando um sentimento de peculiaridade, e de riqueza natural. Também colocam sobre sentimentos bons, que o butiazeiro estimula nas pessoas.

C7: "propriedades medicinais do butiazeiro".

“... ter um valor nutritivo, valor grande em betacaroteno, vitamina $C$, fibras" $(\mathrm{CHB})$.

“... cumpre muito sua função, de uma fruta rica em vitamina $C$ ” $(M G)$.

Os entrevistados colocaram a respeito do conhecimento das propriedades medicinais do butiazeiro, essa categoria expos uma riqueza também de melhoria de qualidade de vida e possibilidade de utilização curativa.

\section{Discussão}

As nacionalidades dos informantes foram de argentinos, uruguaios e brasileiros, uma vez que os butiazeiros ocorrem naturalmente no Brasil, Paraguai, Argentina e Uruguai. No território brasileiro, ocorrem 18 das 20 espécies, do sudoeste da Bahia e leste de Goiás até o Rio Grande do Sul (5).

$\mathrm{Na}$ categoria $\mathrm{C} 1$, muitos foram os fragmentos de depoimentos relatados a respeito da ligação do butiazeiro com a infância dos informantes, exposições que demonstram recordações, "proximidade e intimidade com o butiazeiro". Com essas colocações se demonstra a incidência dessa planta na região, e que propiciar às crianças o contato com a natureza é permitir que ela amplie o seu "ser no mundo", que aprenda a preservar o meio em que vive, que tenha atitudes sustentáveis e conscientes com relação ao meio ambiente (16).

A "importância do butiá" para os integrantes da Rota dos Butiazais, na categoria C2, trouxe explicitado nos relatos a influência atual e futura do butiá, a possibilidade de 
utilização de todas as suas partes, destacando também sua capacidade nucleadora, com as oportunidades que traz para seus arredores e pela forma de poder ser trabalhado em conjunto com a agricultura e pecuária. Além da importância direta que esses recursos têm para as pessoas, as palmeiras são um grupo de plantas-chave na manutenção de muitos ecossistemas tropicais e subtropicais em inúmeros contextos, atuando principalmente como fonte de alimento e abrigo para uma infinidade de animais silvestres (17).

Os informantes colocaram a "preocupação com o risco de extinção" do butiazeiro, na categoria C3. Aliadas ao conhecimento científico, as identidades afetivas e culturais são elementos necessários para o sucesso na conservação da biodiversidade. Ou seja, a manutenção da qualidade ambiental precisa estar conectada ao uso dos recursos naturais, assim como o uso precisa estar associado à sua conservação (1-2).

Também se pensa que o empenho dos pesquisadores e ambientalistas, na divulgação de informações em conjunto com a comunidade, vislumbrando mais possibilidades de utilização da planta, pode possibilitar o cuidado e com isso a preservação. A exploração do butiá ocorre por meio do extrativismo em propriedades rurais onde as plantas encontram-se naturalmente presentes, sendo necessário o desenvolvimento de tecnologias de cultivo e produção (18). O extrativismo também ocorre em quintais urbanos e em margens de rodovias, nas áreas de ocorrência.

Nessa ideia, uma preocupação a mais é a falta de regeneração das populações, já que nos butiazais remanescentes resistem apenas plantas adultas, algumas centenárias, pois a presença de mudas e palmeiras jovens é escassa (19).

Os entrevistados relataram a importância da biodiversidade e preservação do ecossistema de butiazais, na categoria $\mathrm{C} 4$. Os butiazeiros são plantas-chave nas relações ecológicas dos ecossistemas em que ocorrem. Sua polinização por abelhas caracteriza uma interação mutualística, em que estas coletam substâncias oferecidas pelas flores, como néctar, pólen, óleos, perfumes ou resinas, e em contrapartida transferem grãos de pólen entre as flores dos butiazeiros, contribuindo para a variabilidade genética das gerações seguintes $(7,20)$.

Ainda nessa explanação, às vezes são áreas com uma densidade de butiazeiros tão elevada, que se tornam áreas de repouso para os animais. O campo nativo associado aos butiazais serve de alimento para o gado. Também por ser protegida legalmente, preserva o que está ao seu redor. No caso da pecuária, atividade considerada vocação econômica da região pampeana, autores inferiram que a pressão de pastejo do gado reduz muito a renovação do butiazal, restando somente indivíduos adultos na população (2).

Assim sendo, é imprescindível encontrar um ponto de equilíbrio para um manejo de atividades econômicas em áreas de butiazais, promovendo a renovação da planta. A dissertação "Contribuições do manejo conservativo à conservação in situ de Butia odorata (Arecaceae) no Bioma Pampa", traz que, com relação ao ganho econômico pela pecuária na área estudada, os animais, que foram pesados antes e depois do ciclo de pastejo no butiazal, apresentaram um alto índice de ganho de peso (21).

A exposição dos butiazeiros na ornamentação dos pátios e paisagismo urbano, foi colocado na categoria C5. Os butiazeiros também são base para o desenvolvimento de plantas epífitas, como cactos, bromélias, orquídeas e samambaias, que os valorizam ainda mais como elementos de paisagismo. Essas falas destacam que os butiazeiros têm tolerância a baixas temperaturas, característica que resulta de milhões de anos de evolução no bioma pampa $(22,23)$.

Os ecossistemas de butiazais são reconhecidos por seu elevado valor paisagístico, de biodiversidade e histórico-cultural, compreendendo uma valiosa diversidade de flora e fauna nativa associadas. Continuam explicando que, devido à bela arquitetura da planta $\mathrm{e}$ sua resistência a baixas temperaturas, os butiazeiros são usados no paisagismo rural e 
urbano, na composição dos jardins, parques, praças, ruas e avenidas (7-23).

Uma identidade territorial se cria quando os butiazeiros estão presentes no local, fato destacado na categoria C6. O Trabalho de Conclusão de Curso "Estudo do lugar: Giruá e o butiá, manifestações da cultura no espaço", coloca que o butiá, fruto símbolo do município de Giruá, confere singularidade à comunidade local, na medida em que, ao perpetuar a história dos antepassados, valoriza aquilo que lhe é próprio e pertence à cultura local. A culinária, artesanato, poesias e outras manifestações culturais locais são exemplos disso (24).

Quanto ao sentimento de morar em um local com butiazeiros, foi relatado que parece enriquecer o lugar. Nesse sentido, as dimensões da vida constituem campos particulares de investigação da geografia no estudo de uma sociedade local e historicamente determinada pelas relações produtivas, econômicas, políticas, culturais, religiosas que se estabelecem. Além do mais, as experiências geográficas se dão pelos sentidos que mediam as experiências ambientais (24).

Sobre as propriedades medicinais do butiazeiro, na categoria $\mathrm{C} 7$, autores corroboram expondo que os butiás (Butia odorata) apresentam compostos com atividade antioxidante, que trazem benefícios à saúde (24). Também em sua dissertação, "Atividade antibacteriana de extrato de butiá (Butia odorata) contra bactérias patogênicas.", foi demonstrado que o butiá possui atividade antibacteriana, contra bactérias patogênicas (26).

Além de que em âmbito mais geral pesquisas como "Diversidade das plantas brasileiras com potencial anti-helmíntico" apontam que se deve buscar o conhecimento científico das plantas utilizadas com fim medicinal pela população, na maioria das vezes na forma de chá, avaliando as possíveis reações adversas, contraindicações e toxicidade (10).

Dando continuidade na discussão, e olhando o contexto dos dados encontrados nos relatos e das experiências pessoas e coletivas, Serge Moscovici (13), disserta sobre as pessoas e os grupos, coloca que, longe de serem receptores passivos, pensam por si mesmos, pois produzem e comunicam suas próprias e específicas representações, assim como lançam soluções às questões que eles mesmos colocam. Essa inferência se aplica ao grupo de pessoas que compõe a Rota dos Butiazais.

O teórico afirmou que as avaliações sobre o ambiente, no caso desse trabalho, em que o olhar é sobre o objeto butiazeiro, podemos dizer que, são efetivadas mediante um sistema de valores, ideias e práticas construídos socialmente por meio dos quais, indivíduos e comunidades comunicam-se e constroem um código para nomear e classificar os aspectos do mundo, da sua história individual e social, estabelecendo, assim, uma ordem para se orientar no mundo material e social e, deste modo, controlá-lo (13).

As representações sociais dos grupos, nesse caso, do grupo da Rota dos Butiazais, por conseguinte, tornam-se interventoras em muitos processos, dentre eles, "[...] a difusão e a assimilação de conhecimentos, o desenvolvimento individual e coletivo, a definição das identidades pessoais e sociais, a expressão de grupos e as transformações sociais" (14).

No sentido de abarcar questionamentos, as representações sociais se apresentam como ferramentas. Partindo do pressuposto de que o real pode também ser definido como a interpretação que dele fazemos, através da apropriação das experiências vividas em nosso contexto social, podemos sugerir que o estudo das representações sociais, de indivíduos e grupos, apresenta importância significativa quando se trata de compreender pensamentos, comportamentos e ações dos sujeitos (27). Neste caso em específico buscou-se demonstrar, através das falas dos entrevistados, como eles pensam e como se comportam a partir do objeto o butiazeiro.

Desta forma, Tânia do Carmo (28), a partir de leituras de Moscovici, expressa que, como 
produto da sociedade e sua história, as representações sociais acerca dos mesmos objetos e pessoas, como é o caso desse trabalho, não são idênticas para todos os indivíduos e grupos, podendo ser configuradas de formas diversas e, muitas vezes, até antagônicas.

Para Serge Moscovici coloca que a representação social se preocupa com a inter-relação entre o sujeito e o objeto, que no caso em específico é "o grupo da Rota dos Butiazais e os butiazeiros". Também de como se dá o processo de construção desse conhecimento, ao mesmo tempo individual e coletivo, um conhecimento de senso comum, configurandose em um saber tradicional (13).

Finalizando a discussão, justifica-se a escolha da Teoria das Representações Sociais de Serge Moscovici (13), pois o autor explica que quando as pessoas se encontram para "falar, argumentar, discutir o cotidiano, ou quando elas estão expostas às instituições, aos meios de comunicação, aos mitos e à herança histórico-cultural de suas sociedades, é que as representações sociais são formadas".

\section{Conclusões}

A limitação desse estudo, é também seu maior foco, ser específico de um grupo, o da Rota dos Butiazais. Entende-se que o objetivo dessa pesquisa foi alcançado, pois os participantes desta rede descreveram como se sentem em relação ao butiazeiro, e o evento foi palco de troca e soma de saberes, efetivamente construindo as Representações Sociais em relação a planta.

As falas dos informantes foram organizadas de forma a estruturar e mostrar essas Representações Sociais que vão se formando neste grupo. E encontros como este, demostram que está acontecendo o fortalecimento e a organização das ideias que culminam na intenção de preservação e cuidado, tanto das plantas, quanto dos ecossistemas envolvidos.

Acredita-se que trabalhos como este, descrevem ações que vem sendo realizadas, mas que nem sempre são apresentadas ao universo científico. Movimentos que podem servir de balizadores para outros grupos, pois estão dando certo, e muitas produções estão acontecendo, que realmente unem pessoas que almejam estimular o respeito, demonstrar a importância atual e futura dos butiazeiros, através do fortalecimento das suas possibilidades e riquezas.

Finalizando estas realizações tem demonstrando que é possível e salutar a interação amigável entre todas as espécies que convivem nos butiazais, e que essa perspectiva, sim, pode levar a um espaço de vida e de trabalho equilibrado no sentido de conservação da biodiversidade.

\section{Referências}

1. Becker FG, Ramos RAA, Moura L. Biodiversidade. Regiões da Lagoa do Casamento e dos Butiazais de Tapes, Planície Costeira do Rio Grande do Sul. Brasília: SCAN Editoração \& Produção Gráfica; 2007.

2. Rivas M. Conservaçãoe uso sustentável de palmares de Butia odorata [tese]. Pelotas: Universidade Federal de Pelotas; 2013.

3. Wolff LF, Wegner J, Heiden G. Butiazeiros como Flora Apícola para a Produção de Mel na Região Sul do Rio Grande do Sul. Boletim de Pesquisa e Desenvolvimento. [Internet]. Pelotas: Embrapa Clima Temperado; 2016. - [citado em 2020 mai 03] Disponível em: http://www.bdpa.cnptia.embrapa.br/consulta/busca?b=ad\&id=1081697\&biblioteca=vazio\&busca=10 $81697 \&$ qFacets $=1081697 \&$ sort $=\&$ paginacao $=$ t\&paginaAtual $=1$.

4. Rivas M, Barilani A. Diversidad, potencial productivo y reproductivo de los palmares de Butia capitata (Mart.) Becc. De Uruguay. Agrociencia 2004; 8(1):11-20. 
5. Lorenzi H, Noblick L, Kahn F, Ferreira E. Flora Brasileira: Arecaceae (palmeiras). Nova Odessa: Instituto Plantarum; 2010.

6. Sosinski E, Hagemann A, Dutra F, Mistura C, Costa FA, Barbieri RL. Manejo Conservativo: Bases para a Sustentabilidade dos Butiazais. Boletim de Pesquisa e Desenvolvimento. [Internet]. Pelotas: Embrapa Clima Temperado; 2015. - [citado em 2020 jan 05]. Disponível em: https://www.infoteca.cnptia.embrapa.br/infoteca/bitstream/doc/1058122/1/Boletim230.pdf.

7. Rivas M, Barbieri RL. Boas práticas de manejo para o extrativismo sustentável do Butiá. [Internet]. Pelotas: Embrapa Clima Temperado; 2014. - [citado em 2020 fev 02]. Disponível em: http://www.fzb.rs.gov.br/upload/20160429160121boas_praticas_de_manejo_para_o_extrativismo_su stentavel_do_butia.pdf.

8. Barbieri RL, Chomenko L, Sosinski ÊE, Costa FA, Gomes GC, Marchi MM, et al. Butiás: conservação e uso sustentável de Butiá odorata na região do litoral médio do Rio Grande do Sul. [Internet]. Natureza em Revista; 2016. - [citado em 2019 dez 05]. Disponível em: https://www.infoteca.cnptia.embrapa.br/infoteca/handle/doc/1058273.

9. Barbieri RL, Sosinski EEJ, Marchi MM. Projeto de Pesquisa e Desenvolvimento. Conservação, repovoamento e usos dos ecossistemas de butiazais no Rio Grande do Sul. Fundação de Apoio à Pesquisa e Desenvolvimento Agropecuário Edmundo Gastal. [Internet]. Pelotas: Embrapa Clima Temperado; 2017. - [citado em 2020 jan 20]. Disponível em: https://www.sema.rs.gov.br/upload/arquivos/201812/04110725-conservacao-repovoamento-e-usosdos-ecossistemas-de-butiazais-no-rio-grande-do-sul.pdf.

10. Fenalti JM, Baccega B, Mata-Santos T, Santos PC, Scaini CJ. Diversidade das plantas brasileiras com potencial anti-helmíntico. Vittalle 2016; 28: 39-48.

11. Marchi MM, Barbieri RL, Sosinski ÊEJ. [Internet]. Recursos Genéticos e a conservação in situ de ecossistemas de butiazais no Sul do Brasil. Sociedade Brasileira de Recursos Genéticos 2019; 5 (1):14.

12. Betemps C. Rota dos Butiazais faz seminário técnico para valorização cultural e ambiental. Seminário Técnico. [Internet]. Pelotas: Embrapa Clima Temperado; 2016. - [citado em 2019 dez 11). Disponível em: https://www.embrapa.br/busca-de-noticias/-/noticia/14097801/rota-dos-butiazais-faz-seminariotecnico--para-valorizacao-cultural-e-ambiental.

13. Moscovici S. Representações Sociais: Investigações em Psicologia Social. Petrópolis: Vozes; 2015.

14. Jodelet D. Representações sociais: um domínio em expansão. Rio de Janeiro: UERJ; 2001.

15. Bardin L. Análise de Conteúdo. São Paulo: Edições 70; 2016.

16. Cocito RP. [Internet]. A Natureza como espaço educacional: oportunidades para a infância. Colloquium Humanarum 2016; 13 (especial):94-100.

17. Ribeiro RC. Aspectos históricos, demográficos, morfológicos e genéticos de populações de Butia Eriospatha (martius ex. Drude) Beccari (arecaceae) em paisagens contrastantes no Planalto Serrano de Santa Catarina [dissertação]. Florianópolis: Universidade Federal de Santa Catarina; 2017.

18. Franzon RC. [Internet]. Espécies de araçás nativos merecem maior atenção da pesquisa. Revista Cultivar; 2009 - [citado 2019 nov 28]. Disponível em: https://core.ac.uk/download/pdf/15445249.pdf.

19. Barbieri RL. Vida no Butiazal. Brasília: Embrapa; 2015.

20. Rosa L, Castellani TT, Reis A. Biologia reprodutiva de Butiá capitata (Martius) Baccari var. odorata (Palmae) na restinga do município de Laguna, SC. Brasilian Journal of Botany 1998; 21 (3).

21. Hagemann A. Contribuições do manejo conservativo à conservação in situ de Butia odorata (Arecaceae) no Bioma Pampa [dissertação]. Pelotas: Universidade Federal de Pelotas; 2016.

22. Buttow MV, Barbieri RL, Neitzke RS, Heiden G. [Internet]. Conhecimento Tradicional Associado ao Uso de Butiás (Butia spp., Arecaceae) no Sul do Brasil. Revista Brasileira de Fruticultura 2009; 31 (4):1069-75.

23. Tonietto A, Schlindwein G, Tonietto SM. Usos e potencialidades do butiazeiro. Circular Técnica. [Internet]. Porto Alegre: Fepagro; 2009 - [citado em 2020 fev 02]. Disponível em: https://issuu.com/fepagro/docs/circular_26.

24. Richter EM. Estudo do lugar: Giruá e o butiá, manifestações da cultura no espaço [trabalho de conclusão de curso]. Ijuí: Universidade Regional do Noroeste do Estado do Rio Grande do Sul; 2014.

25. Crizel R, Lemke E, Zandoná G, Aranha B, Chaves F. Potencial funcional de polpas de araçá amarelo 
(Psidium cattleianum) e de butiá (Butia odorata). Revista da 14ª Jornada de Pós-Graduação e Pesquisa 2017; 2252-2264.

26. Maia DSV. Atividade antibacteriana de extrato de butiá (Butia odorata) contra bactérias patogênicas [dissertação]. Pelotas: Universidade Federal de Pelotas; 2017.

27. Del Ré M, Rambo AG, Schneider S. As representações sociais nas dinâmicas territoriais do desenvolvimento rural: considerações a partir do Território Zona Sul do Rio Grande do Sul. Estudos Sociedade e Agricultura 2017; 25 (1):57-82.

28. Carmo T, Magalhães CAOJ, Kiouranis NMM, Triani FS. [Internet]. Representações sociais de estudantes do ensino médio sobre problemas ambientais. Revista Brasileira de Estudos Pedagógicos 2018; 99 (252):313-330. 